\title{
Developing English presentation skills as a component of collaboration competence for sustainable development
}

\author{
Nataliia Zaitseva* \\ Dmytro Motornyi Tavria State Agrotechnological University, Department of Foreign Languages, Melitopol, 72312, Ukraine
}

\begin{abstract}
The paper deals with the problem of teaching non-linguistics students English presenting as a component skill of collaboration competence. Students' considerable reluctance to take up this type of creative activity and to present their ideas in front of their colleagues is a serious obstacle to develop their communicative abilities necessary for prospective leaders of the 21 st century in science and industry. The results of the survey of Machine Building and Computer Science students as to reasons for their disinclination to create presentations are presented. The strategy for overcoming students' unwillingness and building their presenting confidence are given. The example of implementation of a task for strategic thinking for sustainable development within the discipline 'English as a foreign language' is given. The aspects and stages of effective online presentation editor application for teaching English presenting are analysed. The results of students' choice of five presentation tools are included. Three prospective online presentation makers are analysed and their utility for creating and giving English presentations are studied. It is stated that the most promising online tool is Prezi since it offers prepared professional quality features and incites developing and incorporating personal creative ideas through bright and uncommon visual means.
\end{abstract}

\section{Introduction}

Abilities to learn, to deduce new ideas from current data, to produce new knowledge and to share it in order to encourage new research are outcomes of the modern university study. Universities must "play an increasingly important role in helping students become responsible and active citizens, with a clear vision of the importance and future challenges of sustainability" [1]. According to the Strategy for Education for Sustainable Development developed by the United Nations Economic Commission for Europe (UNECE), education is a prerequisite for achieving sustainable development. It is essential to equip people with knowledge of and skills in sustainable development, making them more competent and confident [2]. In order to undoubtedly reveal own potential as a valuable asset, a global thinker and a prospective change maker, a present student should be taught adopting an alternative educational approach which includes in addition designing and presenting sustainability projects. The implementation of the sustainability principles into curricula can provide students with all necessary knowledge and skills. But the extent to which this implementation is possible and ranges of disciplines involved are being considered by most universities separately. Since English is the language of global communication, this discipline should inevitably inculcate sustainable development ideas in students. It is crucial for prospective leaders in science and industry of the 21 st century to be able to clear their communicative intention and achieve communication goals in English. Ukrainian graduates in Engineering and IT specialities should be able to help reduce national and global poverty, connect people and enhance common IT competency, create inclusive societies through multinational engineering projects. Ukraine has considerable potential for rapid development of partnerships with the countries of the European Union and in the Northern Hemisphere in the fields of sustainable economics and production. Today, demand on qualified human resources outweighs importance of available material resources in most key industries and IT sphere. The interest of foreign companies in Ukrainian employees is undeniable. However, one of the basic requirements for a professional-to-be with impressive career prospects is according to the study of V. Osadchyi and S. Symonenko [3, 4] advanced English communication skills. Forming communicative skills and command of English are preconditions for educating professionals-to-be as global citizens for sustainable development.

Good command of English supposes demonstrating the level of confident usage of the employer country language and experience in professional and business sphere communication in order to carry out communicative intents as part of the collaboration sustainable development competence. Collaboration (interpersonal) competence ensures that "professionals have an open ear (and language competence)" [5], are

* Corresponding author: natalija_zajtseva@ukr.net 
able to map different perspectives and values and facilitate dialogue. Against this background, formation of English communicative competence of students in the educational process at universities is a prerequisite for their further professional growth and competitiveness worldwide. The collaboration competency skills like ability to present themselves, their ideas and debate on professional issues, to speak out in front of colleagues, to listen actively and to inquire soundly can and should be trained during university studies. Namely these skills are most effectively developed and deepened through giving a presentation.

The analysis of recent scientific and publicist sources indicates also that the preconditions for creative intellectual activity in a foreign language, for motivating students for thorough preparation for foreign language reporting and presenting (accompanied by audiovisual means), and the problem of overcoming psychological and language barrier remain insufficiently explored.

The purposes of this article are to develop an integrated approach to gradual formation of positive students' perception of preparing a presentation, to give an example of implementation of sustainable development issues into a problem task, to present ways of teaching students creating and editing English reports accompanied by online presentation and to analyse particular editors' suitability for teaching students creating English presentations.

\section{Verbal communication as an educational skill of the 21 st century and a component of the sustainable development competency}

The term ,21st century skills" is shifting and blurred as according to different sources it includes a wide range of skills, knowledge, character traits and work habits, associated with $21 \mathrm{st}$ century trends and professional demands.

Awareness about the crucial role of communication skills and the necessity for their inculcation in students to prepare them for becoming today's highly collaborative, innovation-focused workforce brought teaching those skills into foreground of educational field.

In 2006, the program P21 Framework for 21st Century Learning was first published and has been continuously updated [6]. It is a model for incorporating 21 st century skills into learning developed by the alliance of the US Department of Education, businesses (including Apple and Microsoft) and educational organizations. The Framework rests on core academic subjects (like languages and foreign languages) for teaching life and career skills, learning and innovation skills, and information and media skills. The P21's research-based 4C's and most promoted activities are Creativity, Critical Thinking, Communication, and Collaboration.

Bobbi Kurshan, an education entrepreneur and an expert on how innovation and technology are transforming teaching and learning, notes that the term ' 21 st century skills' is often used in educational circles to refer to a range of abilities and competencies including problem solving, communication, collaboration, creativity and innovation [7]. Kurshan also refers to the P21's Frameworks for 21st Century Learning, where she sees her vision of skill list augmented and split into learning and innovation skills (creativity and innovation, critical thinking and problem solving, communication, collaboration) and information, media and technology skills (information literacy, media literacy, ICT literacy). The overlap of both classifications is the necessity of educating in the $21 \mathrm{st}$ century a good communicator able to use all the variety of means to interact with people around the world and flexible about rapid changes in information technology tools.

The Glossary of Education Reform [8] lists 55 items as Skills of the 21st Century, of which we are going to refer to following skills:

1. Critical thinking, analysis, interpretation, synthesizing information

2. Research skills and practices

3. Creativity, innovation, personal expression

4. Oral and written communication, public speaking and presenting, listening

5. Information and communication technology (ICT) literacy, media and internet literacy

6. Scientific literacy and reasoning.

The mentioned before competencies in education for sustainability or competencies for Sustainable Development (ESD) were developed by UNECE. ESD raises awareness of the complexity and dynamism of issues. It also plays a key role in making sustainable development understood and in ensuring it is applied in specific ways. ESD aims to plan specific sustainable actions at all educational levels, favouring the development of competencies that allow people to think about their actions. According to School of Sustainability, ESD goals include: Forming Systems Thinking Competence, Futures Thinking (Anticipatory) Competence, Values Thinking (Normative) Competence, Strategic Thinking Competence and Interpersonal (Collaboration) Competence [5]. Summarizing the concept presented above it should be stated that individuals as part of society must have the power to act in complex situations in a sustainable manner.

The mentioned above skills are closely connected to abilities to achieve communicative intention, to build long-term rapport and consensus and are in our opinion referring to verbal communication as a crucial skill underestimated in Ukrainian education. Nowadays, students tend to communicate using technology, and most of young people are characterized as digital native or media fluent in respect of online socializing. Nevertheless, communicating is more than sharing information and assessing it according to your likes and dislikes. Communication includes personal interaction in the first place but suggests that skills of application of supporting and accompanying means for personal interplay are going to be continuously improved. The examples of such advance are mastering blogging, communicating through video, creating a visual product. 


\section{Presenting in English as education aspect}

Within the Education for sustainable development strategy an English course goals expand and suppose [9]: - working towards making changes in training which leads to increased attention and focus on discipline. We refer to this point by H. Kanuka as increased students' motivation and interest in compulsory and optional learning tasks;

- using technology in ways that create openings. In our opinion, the multi-disciplinary approach is welcome since IT and foreign language synergy enhances outcomes in both disciplines;

- supporting informal learning. Engaging students in creative tasks, in international social projects, encouraging their initiative in form and venue choice is in our view sensible;

- achieving understanding through the use of diverse instructional methods. We would recommend supplementing traditional training techniques with innovative ones, e.g. accompanying a theme scrutiny with application IT tools).

Effective presenting is a multi-component learning goal which should be represented in both modes - within classroom activities and as an integral part of students' independent work. Introducing media education, developing media literacy and creativeness, formation of English media competence, and information technology application at English classes overlap one way or another in training of specialists of non-linguistic specialties. Within the academic disciplines 'English' or 'English for specific purposes', no teacher can guarantee having attracted every student in their classes to giving performances in public. Exemplary public presentations by at least some non-linguistics students often remain an ultimate but promising and unattainable goal. It is therefore sensibly to begin verbal communication improvement in vocational training with instilling in students the basic presenting skills through involving them into creating a small volume captivating presentations on familiar themes and content accompanied by audiovisual media of their choice.

We refer to the concept of L. Milovanova [10] that the term 'presentation' in the context of vocational training in higher education is not just giving a speech in front of an audience with the purpose of persuasion or inducement. It is an act of interpersonal communication, the success of which depends on the level of orator's skills in speaking and communicating. Consequently, a reported text for training goals does not have to be difficult because of the fact that it will be the subject of communication in a foreign language - discussion, dialogue and both criticism giving and accepting. The theme should be disclosed in such a manner and through such speech and visual means that it is comfortable for perceiving and feedback producing by well-informed or at least familiar with the theme audience.

Regarding the mentioned above strategy, we consider the point of view by O. Karpova [11] controversial. O. Karpova insists on the presence of the high level proficiency in a foreign language (B2, CEFR) as a prerequisite for applying by students multimedia technologies while preparing a speaking assignment. In our opinion, even language learning beginners should try giving short presentations. In this way speakers can assure themselves in the possibility of achieving communicative goals through the combination of a simply-structured author's text with adequate audiovisual media.

From the perspective of B. Chivers [12], student presentations have as their main purpose the following aspects:

- persuasion (to join in, to choose the presented theme or the item, etc.);

- training (demonstrating functioning and principles of work of a device or equipment, demonstrating own skill level in working with equipment, sharing own knowledge and experience);

- instructing and studying (forming a broad skill set, looking into a specific area, considering the problem from different perspectives);

- informing (introducing new facts or data, providing a dynamic progress report);

- assessment by a teacher (a teacher can soundly assess whether the student has acquired the intended knowledge and skills).

In fact, most presentations are the result of a combination of the goals mentioned above.

The most accurate classification of presentation types based upon the ultimate goal as a key criterion is provided in our opinion by The Bob Pike Group [13], the educational consultant:

1. Informing

2. Skill formation

3. Progress demonstration

4. Promoting a product or a service

5. Decision making

6. Problem-solving.

However, we insist on the integrated approach to preparing a student presentation as a communication task at the very planning stage. Therefore, a student's performance is going to ideally demonstrate the achievement of at least two logically connected purposes from mentioned above. Considering mediated communication we analyse a student individual oral presentation as a study object, when a student uses software or online editor to create and give their presentation.

Obviously, skillfulness and confidence in English speaking in front of groupmates are rare in classrooms of Engineering specialities. Richard Zeoli's expert opinion is that 'some individuals are definitely born with this gift, the overwhelming majority of effective speakers have trained themselves to be so. Either they have received formal media training or they have delivered so many speeches that over time they've learned what works for them.' [14].

Carmine Gallo, a communication advisor, business communication expert and Harvard instructor appeals to teacher colleagues not to force students to just one presentation but to "give them opportunities to share 
parts of their project or assignments throughout the school year and give them options on how to do so" [15].

Peter Hyman, School 21 cofounder, notes that 'oral communication skills must be explicitly taught like other core skills in school'. We completely support the vision of this skill profit for present generations within the sustainable development framework outspoken by Hyman: 'a well-spoken, confident young person will have occasion to use those communication skills throughout his or her life' [16].

Generalizing three mentioned above opinions, the strategy has been worked out - to start training students to make and give presentations on the examples of short, personally engaging and concise reports accompanied by innovative and prospective visualizing tools.

\section{Ways of building students' presenting confidence}

In the curricula of future engineers in the 'Machine Building' speciality, individual creative assignments are included in the independent work aspect in English as foreign language. There has been developed an online course for distant learning on the Moodle platform [16]. There are two presentations on the themes on students' choice from the fifth term syllabus content. Basing on lexical-grammatical material of the term themes a student must prepare a report on a topic related to studied units from their English coursebook. The report should demonstrate personal experience and viewpoint on the particular problem.

The practical goal of this student independent work type is to consolidate the studied vocabulary, the pedagogical goal is to expand students' world view by studying additional facts and carrying out the thorough analysis of authentic English sources highlighting the importance of sustainable development. The educational goal focuses on creating appropriate system of linguistic concepts for discussion leading in the formats of a plenary session or of a face to face discussion. It also aims at raising general etiquette rules and speaking culture awareness during the conduct of a controversy or while holding a debate. The developmental goals include formation of speaking skills and building performing confidence, increasing readiness for conducting discussions with numerous opponents, improving automation skills in software using for the visualization of the report (ideally, an editor with a particular foreign language interface).

English learners in their first term mostly look into individual creative tasks reluctantly. The first reason for lack of enthusiasm is that individual work format and presentation as the form of sharing its results in plenum is unusual. Secondly, presenting in the humanities supposes fluent speaking but Engineering and IT students often consider themselves insufficiently creative or trained for public performances. Most students are not eager to give presentations in English even in front of their not numerous groupmates.

To motivate students for the above mentioned types of independent work, a number of steps have been taken, the first of which was the survey on difficulties demotivating students. The survey involved 54 undergraduate students (2-4 years) of 'Machine Building' and 'Computer Science' specialities of Dmytro Motornyi Tavria State Agrotechnological University. First, the students themselves have given arguments for and against giving presentations in English in the panel discussion. The outspoken objections were generalized and formed into two groups. Group 1 was supported by 38 students and focused on lack of enthusiasm in respect of giving presentations in any discipline. Group 2 (supported by 43 discussion participants) embodied students' concerns about not being able to overcome difficulties arising during preparing a presentation in English.

The second step taken to persuade students into public speaking was the detailed analysis of their reasons above: the counter-arguments (like professional necessity to present agendas, designs, reports etc.) were presented and the effective measures (like additional training, group projects with participants' workload and roles reasonably divided etc.) were suggested.

Among the generalized reasons for their reluctance to submit individual creative activity in the presentation form (group 1) the students have named the following issues which the teacher has opposed respectively referring to the sustainable development strategies and 21 st century skills crucial for professional growth in globalized job market:

1. Dislike of presenting in general. As a counterargument to overcome the natural modesty the teacher offered examples of mini-presentations in everyday life, which students embody regularly (such as presenting a new device to friends or telling them a travel story).

2. Foreignness of public speaking to Engineering and Computer Science spheres. The teacher has listed numerous examples of an employee's tasks, such as presenting their own achievements during job interviews, presenting a project to subordinates, reporting on a completed assignment to customers, training new subordinates, instructing trainees.

3. Time-consuming preparation. To mitigate this problem, the teacher has offered a number of sources and Internet resources providing information on the topics that are being studied in a particular English course. The resources are classified according to themes and language reference levels. In addition, student independent work in the form of presentation is correspondingly assessed (scores for successful problem research and its visual representation, prepared speaking and skillful coordinating after-presentation discussion are twice higher than regular scores for class work.)

Among the reasons for their unwillingness to explore specific suggested themes (which can be applied to most topics in English courses in every study year) students have listed (group 2):

1. Lack of confidence in their English proficiency level. The teacher has offered and provided some advice and assistance in research material simplification, presentation text writing and speaking training ensuring correct pronunciation and intonation. 
2. Poor knowledge on the topic of the alleged report to be presented. An example is the theme 'Planning sustainable cities in the 21 st century'. The theme is composed based on the worked over video material of the coursebook - Navigate (Oxford University Press) [18]. The short film demonstrates how increasing number of high-rise buildings in London changes the metropolis. Not only the horizon line change but also social aspects in the city are explored: new jobs and business blocks in a particular area appear as a result of large-scale building construction. The presentation theme is derived from the video but does not reflect it because it includes the sustainable development aspect for students' consideration and suggests an individual agendum. Students are encouraged to present their own perspective on:

1) increasing resource and energy-efficiency in the city where their university is located,

2) designing spatial arrangement of inclusive pathways and streets for women, children, seniors and persons with disabilities,

3 ) founding the necessity and location of urban economic and social facilities for empowering local communities,

4) accelerating switch to the accessible and sustainable transport system for all,

5) providing inclusive and accessible green and public spaces.

To help the students the teacher has listed a number of Internet sources that represent the sustainable development goals [19] and a civic administration website which soundly and closely represents the agenda, statistics and factual data. It can be the link to the city council website where the students can get familiar with the projects of building construction and the renovation plans and timing. Students can compose a complete report and visualize it with online editors or Power Point using the mentioned above data combined with presenting their own experience (convenience or inconvenience, sustainability and the inclusion level of their neighborhood) or comparing two quarters of the city (a block of single-floor houses with driveways and small gardens and newly built office buildings in the city centre), or making a proposal to change or to improve the urban design).

3. Too large volume of material that should be analysed and compressed. An example of such a topic is 'Preparing for public speaking' in Business English course - Internet resources offer a variety of links to extended text, graphic and video materials. To help the students, the teacher carries out a brief training on the principles of printed text compression. Through individual counseling and looking into a theme together with a potential speaker, the teacher supervises their designing a report outline on a specific topic.

4. The inability to include personal experience in the report. In this case, the teacher can offer the students to present their own point of view. For example, if the report 'The world's most famous achievements and world records' cannot demonstrate students' world famous success, it can be represented in the form of a rating with reasonable explanation of ranking each item in a particular place. The criteria could be the importance of the achievement for the sustainable development, for the mankind, or the scale of raised funds, or effort put into the record, future prospects etc.). Alternatively, students can list several activities in which they dream (or at least would like) to express themselves, as well as the reward, which they consider fair or valuable for themselves or for other people.

\section{Teaching Engineering students creating English presentations with online presentation software}

In case of excluding complexity of composing a text part, students have no objections to the submitted creative task form. None of 54 surveyed Engineering and Computer Science students of Tavria University has avowed lack of skills or a low skill level in using software to create a presentation as a report's accompanying visual component. Nevertheless, the mostly referred to means of visualization was Microsoft Power Point. Selecting visuals for designing slides to accompany the report is considered by the students the most interesting (and the easiest) stage in creative task preparation.

As an additional incentive to exert maximum effort to prepare a presentation, it is offered to familiarize students with online presentation editors with a foreign language interface. Among numerous benefits of online presentation editors over desktop software namely their novelty is one of the most captivating. Among the survey respondents, only two students have worked with one of the online editors (Prezi). It should also be noted that abilities of competitive software (Haiku Deck, PowToon, SlideShare, Slidebean, Prezi, Beautiful.ai, Canva etc.), and even the fact of their existence and popularity in the English speaking Internet environment was a real discovery for most students.

The goal of presenting within a group at classes includes training skills as both a monologue on the prepared materials and script, and spontaneous speaking, which is a prerequisite for preparing presentations of scientific research results at student conferences in Alma mater, and at conferences at other universities. It should be noted that the usage of online editors in the first phase (in their own student group) often stimulates students to a more creative text and visual representation, encourages more free manner when speaking (for example, when the statement or the applied visual tricks find groupmates' approval) and in dealing with discussion questions.

The second stage of presenting skill training takes place in a more sophisticated environment of science conference sections. Wide visual abilities largely become fundamental to transform formal research materials in a report text into innovative scientific solution in the course of speaking. Accompanied by an online presentation a scientific report can be presented understandably and, most importantly, captivating even for non-experts in a particular area.

To familiarize students with the English interface of 
high-performance and unusually creative online editors a teacher has to conduct thorough preparatory work. Firstly, it is necessary to create atmosphere of eagerness and motivation to acquire new knowledge and skills in student audience. One of the options is to show a promotional video of a specific service for online presentations in which professional marketers have already collected the best abilities of the product. Another (equally effective) option is demonstrating a fascinating presentation of a senior student (who has participated in a scientific conference with a report accompanied by a 'non-standard' online-presentation). A teacher's promise to help everyone to learn how to create such impressive English products in the Englishinterface editors is a strong incentive for students.

Secondly, a teacher should make sure that the classroom intended for demonstrating online editor advantages is rigged with all the necessary technical equipment and devices. At the stage of introducing of operation and differences of online-editors from desktop software a teacher is going to need:

1) a computer with Internet connection, big TV or multimedia projector;

2) their own profiles of a registered user for each online presentation editor, which is going to be demonstrated to students;

3) various digital content (such as audio recordings, documents in different formats and different types of images) for current demonstrating of online editing;

4) handouts presenting keywords (as appropriate a wordlist) and a list of instructions.

Handouts are actually the third prerequisite for successful interaction between a teacher and students when investigating online editor utility. Handout cards or worksheets should contain lexical units required to work with any software ('open', 'add', 'copy' etc.) and the vocabulary only inherent in certain online editors (for example, 'style library' in the editor named PowToon, 'deck' in Haiku Deck, 'discoverability score' in SlideShare). After having done several tasks for expanding students' vocabulary it is reasonable to proceed to gradually familiarize students with online applications.

The best way to introduce the principle of operation of a particular online editor is giving live performance of online presentation editing. Using the prepared digital materials the teacher is explaining in detail their actions and commenting on the result in the foreign language. In such a way the teacher $\operatorname{logs}$ in to the working environment of each online editor aimed to be studied one after another. The teacher creates simple presentations under the same scenario or plan. It is sensible to demonstrate applying the most important functions (adding text or multimedia, formatting tables, zooming, customizing and turning slides) and interesting options specific to a certain online editor (for example, changing the font size with a very comfortable bar with a slider while previewing the result in the Slidebean online editor or zooming and rotating separate elements or whole slides in Prezi).

Having watched the editing and presenting processes with 5 different online presentation makers (Prezi [20],
Keynote [21], Canva [22], Beautiful.ai [23], Haiku Deck [24]) performed by their teacher students have ascertained that it is quite possible to create a presentation online easily and give it more vividly and impressively. All 54 students having participated in the discussion mentioned above have stated their intention to try creating and giving presentations with online editors.

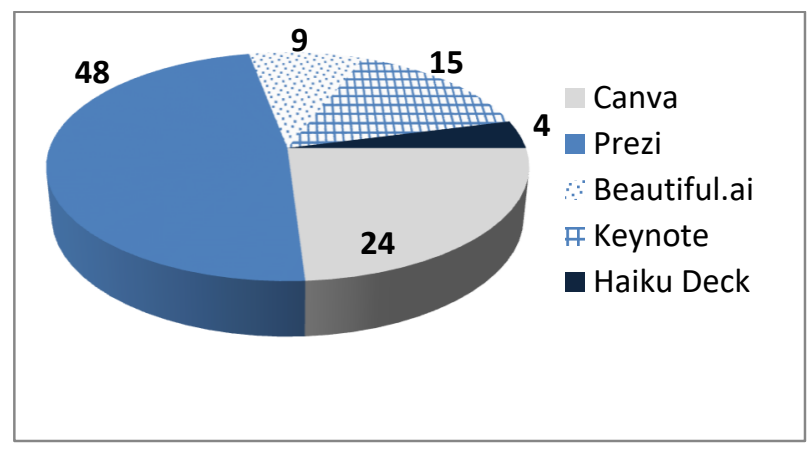

Fig. 1. The results of the survey on the most prospective online presentation makers for presenting in English.

Three web browser presentation makers of five have been chosen by students through a survey. The criteria for opting were user-friendliness, variety of editor features and outcome impressiveness. The results of the survey are represented in the diagram (Figure 1). The majority of students have opted for Prezi, Keynote and Canva.

The most effective and widely used PowerPoint alternative is a presentation tool named Prezi [20] - a web-based presentation software with more than 60 million users worldwide.

It is especially popular with entrepreneurs und educators thanks to customized pricing and follow-up policy. However, only paying subscribers have the option to assign privacy rights. Anyone can find and view prezis from free accounts.

Providing a wide range of completely free functions (there are upgrades a user can pay for to unlock additional features), Prezi gradually gains more premium subscribers offering some unique features like motion, zoom, and spatial relationship. One large canvas is a scalable background which allows zooming various frames or visuals of the canvas and therefore emphasizing the presented ideas effectively. A user can add their own content to communicate ideas more impressively and to make a particular prezi more engaging to viewers. Prezi runs entirely through web browsers, excluding compatibility issues. Accessing prezi from a mobile device on a device's web browser is very convenient as well as a Prezi Viewer app available for both iOS and Android. Other inviting features are: remote presenting, injecting individuality into a presentation, innovative thinking, real-time collaboration, supporting text, images and video.

Keynote for Mac [21] enjoys wide popularity with Apple users because of Apple device synchronization. A presenter can move from their Mac to iPhone or iPad and vice versa. Keynote offers a great amount of impressive templates, fonts, charts, columns, bars, pies, scatters, bubble charts. A presentation is easy to create - a user 
may simply compound available elements and add their own data within. A specifically promoted unique Keynote feature is 'Magic Move' - it animates an object between two slides. Keynote and PowerPoint compatibility is stressed, though it is noted that a presentation of a particular complexity level is going to be easily created by a lay person in Keynote but its Power Point version needs a skillful user. Other advantages of Keynote are: it offers exclusivity (like using .key (presentation files) and .kth (theme files) bundles alongside other file formats), it's free on all iPhone, iPad, and Mac devices, has intuitive design tools, allows adding illustrations and handwritten comments with Apple Pencil on iPads.

Canva [22] is a free presentation tool which slogan is 'Become a visual communicator'. In order to attract users Canva promotes hundreds of professionally designed layouts and over 1 million stock images (either free or premium - priced at $\$ 1$ ) to create presentations on any topic. The most appealing feature among active social media users is availability of graphics for any social media platform (pre-sized social media image, sharing a canvas to get comments, sharing a project to allow collaborators to edit). Customers also highly estimate easy editing, sending/sharing canvas and webpage navigation. To simplify access from any devices free iOS and Android apps can be downloaded. It should be noted, that free Canva designs are easily downloaded in a range of file types. Nevertheless, all the premium design elements are to be paid for before downloading.

At this stage the teacher revealed also particular presentation makers' features like pricing connected limitations and available languages. Keynote is available in Russian and Ukrainian and other 31 languages, Canva - in 117 languages, Russian and Ukrainian are on the list. It is unreasonable to order students to use English interface only because of online translator accessibility. Instead, it is sensible to motivate potential speakers to do slide editing intuitively, unless they have learned the key words beforehand. Another way of improving the vocabulary for creating and presenting is to shift students' attention towards Prezi, to stress its visual peculiarity and prospects for creativeness since Prezi is available in 9 languages only; among them neither Russian nor Ukrainian are available.

The main features of three applications for online presentation creating and presenting opted for by the students are given in Table 1.

Table 1. Main features of the online presentation software.

\begin{tabular}{|l|l|l|l|}
\hline & $\begin{array}{c}\text { Ready-made } \\
\text { professional } \\
\text { quality templates }\end{array}$ & \multicolumn{1}{|c|}{$\begin{array}{c}\text { Unique } \\
\text { features }\end{array}$} & \multicolumn{1}{|c|}{$\begin{array}{c}\text { Collaborative } \\
\text { editing }\end{array}$} \\
\hline Prezi & free & $\begin{array}{l}\text { zooming, } \\
\text { object rotating }\end{array}$ & up to 10 people \\
\hline Keynote & free & $\begin{array}{l}\text { Magic Move, } \\
\text { writing with } \\
\text { Apple Pencil }\end{array}$ & $\begin{array}{l}\text { up to people } \\
\text { signed in to } \\
\text { iCloud }\end{array}$ \\
\hline Canva & free, premium & - & $\begin{array}{l}\text { up to 3000 free } \\
\text { team members }\end{array}$ \\
\hline
\end{tabular}

After having discussed all the presentation editors, students have chosen by vote one online editor - Prezi, which seemed to them most productive and attractive. Namely with this chosen web browser presentation maker the student group has continued their work. Under the teacher's guidance students have signed up and logged in, created their profiles and have read and accepted the license agreement in English.

In case of split decision on one editor for the collaborative review, the home task for not agreeing to majority choice students can be logging in to another (competitive) online editor and exploring its basic functions as a registered user. The home task for the rest of the group may be composing written instructions on using the basic functionality of the chosen online presentation maker.

The next stage is teaching students embodying their ideas into texts appropriately in order to present them with an online presentation maker (in this case Prezi). The preconditions for successful narrative and visuals combination are:

1. Visual means should be chosen in correspondence with the narrative. Both theme and text style are crucial for creating visual accompaniment to reports. Online editors offer a wide range of bright templates and elements, options and effects. Nevertheless, the task is to present an idea and to achieve communicative goals (to inform, to convince, to engage the viewers) and not to demonstrate all the possible features of a particular presentation maker.

2. A well-thought structure. The text should have clear introduction, body and conclusion. Progressing should be reflected through slides entitled correspondingly.

3. Ideas in every section and successive subsection should be brought out in a presentation through scaling font size, highlighting or underlining.

4. Every unoriginal data or idea (usually cited in a text by placing quotation marks and brackets with reference list number) should be referred to through verbal authors /source mentioning and through corresponding comprehensive slide inscription.

5. Every external link a speaker refers to (a video, background materials or reference tools) should be introduced and the reason of their inserting into the presentation should be explained orally.

6. Every controversial or debatable issue should be presented as a separate slide or object in order to be accessed quickly in the course of post-presentation discussion.

7. It should be stressed that using online editors could influence report timing. Soundly selected options (like animating and zooming) can enhance progressing while viewers look into numerical data, when contrasting and deduction making are intended. On the other hand, excessive text or data amount on a particular slide can cause prolongation in its scrutiny.

8. Even experienced presentation editor users should train and preview their performance several times in order to make sure it is captivating, well balanced, does not shift viewers' focus towards text or visual means, proves speakers' sense of timing. 
To sum up all the mentioned above strategies it should be inculcated in potential speakers that using an online presentation maker can be highly productive and can help them to stand out against other speakers whose reports are accompanied by less impressive visuals. However, creating presentation in an online editor takes up much more meticulous preparation, enlarges design timetable and demands thorough training.

As far as a teacher is concerned, after detailed explanation, a well-founded persuasion speech, demonstrating online editor impressiveness by personal example (giving a presentation to students) and assisting inspired beginners in working out a web browser presentation, a teacher can benefit from their efforts: students understand the sustainable development presence necessity and are able to discuss it; they know the principles of speaking and are able to share ideas, to impress and to build consensus verbally in their future engagements; they are able to choose appropriate visual accompaniment to achieve their communicative goals, their presentations look bright and up-to-date. Therefore, multiple presentation assignments within an academic discipline have a distinct advantage when teaching Engineering and Computer Science students creating and giving English presentations. While cooperating with a teacher and creating their own product within the educational approach to training application of online presentation makers students experience the interactive, learner-centered and action-oriented pedagogy technique which is one of the crucial elements of Education for Sustainable Development developed by UNESCO.

\section{Conclusions}

In conclusion it should be stated that purposeful improvement of communication skills should be an inevitable component of educational activities in English as academic discipline in accordance with the 21st century skills strategy and sustainable development goals. A presentation accompanied with online editors is the most promising task, because students are trained to use an English interface application, to compose a narrative of specific format in order to balance their presentation, inculcated interactive speaking strategies. Students are willing to learn about new means to express themselves and able to soundly opt for the most suitable for them online presentation maker. The role of successful presenting should not be underestimated by students themselves, because it performs the informing, developing, assessing and educating functions and ensures teaching and learning to think and act for themselves according to the Learning Outcomes of Education for Sustainable Development strategy.

\section{References}

1. C.B. Aktas, R. Whelan, H. Stoffer, E. Todd, C. Kern, J. Clean. Prod. 106 (2014)

2. Strategy for Education for Sustainable Development (UNECE. Sustainable Development Goals, 2020), https://www.unece.org/ru/env/esd.html. Accessed 05 Feb 2020

3. S. Symonenko, V. Osadchyi, in MEES'19: Peculiarities of English Language Training for Electrical Engineering Students at Ukrainian Universities, IEEE International Conference on Modern Electrical and Energy Systems, Kremenchuk, Ukraine (IEEE, 2019), pp. 394-397

4. S. Symonenko, V. Osadchyi, Information Technologies and Learning Tools 58(2), 38-48 (2017)

5. Key Competencies in Sustainability (ASU's School of Sustainability, 2020), https://static.sustainability.asu.edu/schoolMS/sites/4/ 2018/04/Key Competencies Overview Final.pdf. Accessed $07 \overline{\text { Feb }} 2020$

6. Framework for 21st Century Learning (Battelle for Kids, 2019), https://www.battelleforkids.org/ networks/p21/frameworks-resources. Accessed 03 Feb 2020

7. B. Kurshan, Teaching 21st Century Skills For 21st Century Success Requires An Ecosystem Approach (Forbes Media LLC, 2020), https://www.forbes.com/sites/barbarakurshan/2017/0 7/18/teaching-21st-century-skills-for-21st-centurysuccess-requires-an-ecosystemapproach/\#75a1b14b3fe6. Accessed 04.02.2020

8. 21st Century Skills (The Glossary of Education Reform, 2016), https://www.edglossary.org/21stcentury-skills/. Accessed 02 Feb2020

9. H. Kanuka, Characteristics of effective and sustainable teaching development programmes for quality teaching in higher education. Higher Education Management and Policy (2010). doi:10.1787/hemp-22-5kmbq08ncr25

10. L. Milovanova, Izvestiya BGPU. Teoriya i metodika obucheniya i vospitaniya 5(69), 127-131 (2012)

11. O. Karpova, in Navchannia inozemnoi movy maibutnikh ekonomistiv zasobamy multymediinykh tekhnolohii (Teaching Economists-to-be a foreign language by means of multimedia technology). (Instytut obdarovanoi dytyny, Kyiv, 2016), pp. 23-24

12. B. Chivers, M. Shoolbred, A Student's Guide to Presentations (SAGE Publications, London, 2007), pp. 2-6

13. 6 Different Types of Presentations (The Bob Pike Group, 2020), https://www.bobpikegroup.com/resources/trainerblog/presentations. Accessed 02 Feb 2020

14. R. Zeoli, Public Speaking in the Twenty-first Century (The International Institute of Debate, 2020), http://iidebate.org/public-speaking/. Accessed 04 Feb 2020

15. C. Gallo, Don't Abolish In-Class Presentations, Teach Students To Enjoy Public Speaking (Forbes Media LLC, 2020), https://www.forbes.com/ sites/carminegallo/2018/09/23/dont-abolish-in-classpresentations-teach-students-to-enjoy-publicspeaking/\#7b576d527ccb. Accessed 02 Feb 2020

16. P. Hyman, Why The Art of Speaking Should Be Taught Alongside Math and Literacy (MindShift, 2016), https://www.kqed.org/mindshift/46546/why- 
the-art-of-speaking-should-be-taught-alongsidemath-and-literacy. Accessed 05 Feb 2020

17. English as a foreign language for Machine Building students (NIP TSATU, 2020), http://nip.tsatu.edu.ua/course/view.php?id=3271. Accessed 05 Feb 2020

18. J. Hughes, K. Wood, Navigate: Coursebook with video (Oxford University Press, Oxford, 2015)

19. UNESCO and Sustainable Development Goals. (UNESCO, 2020), https://en.unesco.org/sustainabledevelopmentgoals. Accessed 10 Feb 2020

20. Presentation Software. Online Presentation Tools. (Prezi Inc., 2020), https://prezi.com/. Accessed 05 Feb 2020

21. Keynote. Beautiful presentations for everyone. By everyone (Apple Inc., 2020) https://www.apple.com/uk/keynote/. Accessed 05 Feb 2020

22. Canva. Design anything (Canva, 2020), https://www.canva.com/. Accessed 05 Feb 2020

23. Beautiful.ai. Be proud of what you present. (Beautiful.ai, 2020), https://www.beautiful.ai/. Accessed 05 Feb 2020

24. Haiku Deck. Beautiful presentations without the struggle (Haiku Deck, Inc., 2020), https://www.haikudeck.com/. Accessed 10 Feb 2020 